\title{
Lactoferrin in the Preterm Infants' Diet Attenuates Iron-Induced Oxidation Products
}

\author{
TALKAD S. RAGHUVEER, ERIN M. McGUIRE, SEAN M. MARTIN, BRETT A. WAGNER, \\ CHARLES J. REBOUCHÉ, GARRY R. BUETTNER, AND JOHN A. WIDNESS
}

Departments of Pediatrics [T.S.R., E.M.M., C.J.R., J.A.W.] and Internal Medicine [B.A.W.], and Free Radical and Radiation Biology Program [S.M.M., G.R.B.], The University of Iowa, Iowa City, Iowa 52242, U.S.A.

\begin{abstract}
Free radical injury is thought to play a significant role in the pathogenesis of several disease processes in low birth weight premature infants including retinopathy of prematurity and necrotizing enterocolitis. Because iron is a known catalyst in free radical-mediated oxidation reactions, the objectives of the present in vitro studies were to determine whether after exposure to air 1) iron present in infant formula, or that added to human milk or formula as medicinal iron or as iron contained in human milk fortifier, increases free radical and lipid peroxidation products; and 2) recombinant human lactoferrin added to formula or human milk attenuates iron-mediated free radical formation and lipid peroxidation. Before adding medicinal iron to formula and human milk, significantly more ascorbate and $\alpha$-hydroxyethyl radical production and more lipid peroxidation products (i.e. thiobarbituric acid reactive substances, malondialdehyde, and ethane) were observed in formula. After the addition of medicinal iron to either formula or human milk, further increases were observed in free radical and lipid peroxidation products. When iron-containing human milk fortifier was added to human milk, free radicals also increased. In contrast, the addition of aporecombinant human lactoferrin to formula or human milk decreased the levels of oxidative products when medicinal iron or
\end{abstract}

\section{ABSTRACT}

human milk fortifier was present. We speculate that the presence of greater concentration of iron and the absence of lactoferrin in formula compared with human milk results in greater in vitro generation of free radicals and lipid peroxidation products. Whether iron-containing formula with lactoferrin administered enterally to preterm infants will result in less free radical generation in vivo has yet to be established. (Pediatr Res 52: 964-972, 2002)

Abbreviations
$\alpha$-OHet, $\alpha$-hydroxyethyl free radical
apo-r-Hu-Lf, apo-recombinant human lactoferrin
Asc ${ }^{-}$, ascorbate free radical
EPR, electron paramagnetic resonance
HMF, human milk fortifier
holo-r-Hu-Lf, holo-recombinant human lactoferrin
MDA, malondialdehyde
POBN, $\alpha$-(4-pyridyl-1-oxide)-N-tert-butylnitrone
r-Hu-Lf, recombinant human lactoferrin
TBARS, thiobarbituric acid reactive substances
SOD, superoxide dismutase
Lf, lactoferrin

With increasing survival of very low birth weight premature infants, the number of such infants at risk for developing intraventricular hemorrhage, periventricular leukomalacia, retinopathy of prematurity, bronchopulmonary dysplasia, and necrotizing enterocolitis has increased. Although still speculative, the pathogenesis of these conditions has been linked to free radical injury (1). Iron added to infant formula or breast milk has the potential of exacerbating free radical oxidation through its role as a catalyst in oxidative reactions (2). Al-

Received May 25, 2001; accepted July 4, 2002.

Correspondence: Talkad S. Raghuveer, M.D., 3043 Wescoe Building, University of Kansas Medical Center, 3901 Rainbow Boulevard, Kansas City, KS 66160-7358, U.S.A.; e-mail: traghuveer@kumc.edu

Supported by NIH HL46925 (J.A.W.), NIH CA66081 (G.R.B.), and NIH CA81090 (G.R.B.).

DOI: $10.1203 / 01 . P D R .0000036362 .22060 .8 E$ though the use of iron-fortified infant formulas to prevent iron deficiency anemia among term infants has been a major public health success (3), the risks and benefits of this approach for premature infants is uncertain. Premature infants are at high risk for developing iron deficiency as storage iron becomes depleted during the period of rapid postnatal growth $(4,5)$ and also at risk of oxidant injury as a result of their lower levels of endogenous antioxidant enzymes and their lower concentrations of free-radical scavengers when compared with their full-term counterparts (6-9).

It has been recommended that enteral iron supplementation be started in very low birth weight infants by 8 wk of life (10, 11). Despite these recommendations and the paucity of the necessary risk-benefit data, premature infants are commonly introduced to iron-fortified formula in their first enteral feedings. Strategies for reducing iron-mediated free radical gener- 
ation while at the same time providing sufficient iron for normal growth and development are likely to benefit premature infants. Lactoferrin, a member of the iron-binding transferrin protein family, inhibits formation of reactive oxygen species by binding iron and thus attenuating oxidation (12). Although Lf is abundant in human milk (13), it is not yet included as an additive in iron-fortified infant formulas. In the present in vitro study, we hypothesize that dietary iron supplements given in the form of iron-fortified infant formula, medicinal iron, or HMF contribute to iron-mediated oxidation, which in turn can be inhibited by the addition of r-Hu-Lf. In testing this hypothesis, our objectives were 1 ) to determine whether iron present in infant formula or that added to human milk or formula as medicinal iron or as iron contained in HMF increases free radicals and lipid peroxidation products after exposure to air; and 2) to test whether r-Hu-Lf attenuates iron-mediated free radical formation and lipid peroxidation when added to human milk or infant formula.

\section{METHODS}

This study was approved by the University of Iowa Institutional Review Board.

\section{Basis for In Vitro Modeling in Premature Infants}

A telephone survey of neonatal intensive care units in the United States indicated that a majority administered medicinal iron supplements to premature infants on once a day basis in close proximity to a feeding. To mimic this practice in vitro, we added iron to human milk or formula in an amount equivalent to that which would provide a $1.5-\mathrm{kg}$ preterm infant with 2 or $6 \mathrm{mg}$ of elemental iron per kilogram per day. Because we assumed that the infant's daily enteral intake would be 130 $\mathrm{mL} / \mathrm{kg}$ divided evenly in eight feedings, the volume of individual feedings given at 3-h intervals would be $16.25 \mathrm{~mL} / \mathrm{kg}$.

\section{Human Milk, Infant Formula, HMF, Medicinal Iron Preparations, and Test Reagents}

Before analysis, human milk samples were stored at $-20^{\circ} \mathrm{C}$ and experiments were performed within 24 to $48 \mathrm{~h}$ of collection. Enfamil HMF (Mead Johnson Nutritionals, Evansville, IN, U.S.A.) designed to supplement human milk for rapidly growing premature infants was also studied because it provides a substantial additional source of iron, i.e. $14.4 \mathrm{mg}$ of iron/L when added to human milk as intended. Commercially available ready-to-feed liquid formulas used for term infants included Enfamil With Iron (20, 22, 24 calories/ounce) and Enfamil Low Iron (24 calories/ounce). The preterm formula studied was Enfamil Premature With Iron (24 calories/ounce; Mead Johnson Nutritionals). Experiments were conducted at room temperature.

The medicinal iron preparations studied included 1) ferrous sulfate (Major Pharmaceuticals, Livonia, MI, U.S.A.); 2) ferric ammonium citrate (Feosol; SmithKline Beecham, Pittsburg, PA, U.S.A.); 3) ferrous fumarate (Feostat; Forest Pharmaceuticals, St. Louis, MO); 4) polysaccharide-iron complexes (Nu Iron and May Vita; Merz Pharmaceuticals, Greensboro, NC, U.S.A.; Ni-Fe-rex; Schwarz, Milwaukee, WI, U.S.A.); and 5) ferric polymaltose (Maltofer; Vifor International AG, St. Gallen, Switzerland). Solutions of apo- and holo-r-Hu-Lf (Agennix, Houston, TX, U.S.A.) and desferrioxamine (Desferal, Sigma Chemical Co., St. Louis, MO, U.S.A.) were made up in $0.9 \% \mathrm{NaCl}$. The concentrations used are reported as the final concentration present in the human milk or infant formula samples being tested.

\section{Free Radical Markers of Oxidative Stress}

EPR spectroscopy was used to measure free radical concentrations in milk and formula. Two different free radical products of oxidation, $\mathrm{Asc}^{-}$and the carbon-centered $\alpha$-hydroxyethyl radical $\left(\mathrm{CH}_{3} \mathrm{CHOH}\right.$, abbreviated as $\alpha$-OHet $)$ were measured. Asc ${ }^{-}$is a relatively long-lived (seconds to hours, depending on the $\mathrm{pH}$ and $\mathrm{Asc}^{-}$concentration) real-time indicator of oxidative stress arising from ascorbate naturally present in human milk or as an additive to formula $(14,15)$. Because of the effect of $\mathrm{pH}$ on $\mathrm{Asc}^{--}$concentration, the $\mathrm{pH}$ of human milk or formula, with or without additives, was measured before each experiment using a pH meter (model 10501, Broadley James Corp, Santa Ana, CA, U.S.A.).

In contrast to $\mathrm{Asc}^{-}, \alpha$-OHet and many other radicals are too short-lived to be detected directly by real-time EPR. Instead, these short-lived free radicals are detected by the use of "spin traps," i.e. exogenously administered chemical probes that form stable nitroxide spin adducts. They have the advantage of being less affected by $\mathrm{pH}$ than $\mathrm{Asc}^{--}$. Ethanol readily reacts with strong one-electron oxidants, such as hydroxyl radical (HO) or oxidants formed by ferrous iron and dioxygen $\left(\mathrm{O}_{2}\right)(2)$, to produce the transient $\alpha$-hydroxyethyl free radical, $\alpha$-OHet. When $\alpha$-OHet from ethanol $(10 \mathrm{mM})$ is spin trapped using $\alpha$-(4-pyridyl-1-oxide)-N-tert-butylnitrone (POBN, 25 $\mathrm{mM}$; Aldrich Chemical, Milwaukee, WI, U.S.A.), it produces the long-lived spin adduct, $\mathrm{POBN} / \alpha$-OHet, which is readily detectable by EPR (16).

EPR spectra were recorded at room temperature using a Bruker EMX spectrometer (Karlesruhe, Germany), equipped with a $\mathrm{TM}_{110}$ cavity and $10-\mathrm{mm}$ flat cell. EPR settings were $100 \mathrm{kHz}$ modulation amplitude, $40 \mathrm{~mW}$ nominal microwave

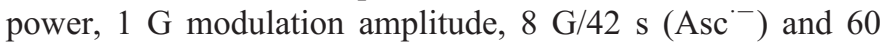
$\mathrm{G} / 82 \mathrm{~s}(\mathrm{POBN} / \alpha-\mathrm{OHet})$ sweep rate, and $655 \mathrm{~ms}\left(\mathrm{Asc}^{-{ }^{-}}\right)$and $84 \mathrm{~ms}(\mathrm{POBN} / \alpha-\mathrm{OHet})$ time constant. Asc ${ }^{-}$and $\alpha$ - OHet concentrations were determined from the averaged signal heights of 10 different spectra per sample. This was done by using a known reference sample and peak height converted to nanomolar concentrations. 3-Carboxy-proxyl $\left(\epsilon_{234}=2370\right.$ $\mathrm{M}^{-1} \mathrm{~cm}^{-1}$ ) (17) was used as the standard for both the Asc ${ }^{-}$ and POBN experiments, taking into account saturation effects (18). Because in the absence of oxygen there is no detectable free radical production in the formula, in all experiments formulas were exposed to air before EPR measurement (19).

\section{Lipid Peroxidation Markers of Oxidative Stress}

Although lipids abound in both human milk and formula, the lipid composition of each differs markedly. To examine the extent of lipid peroxidation, three different complementary indicators were measured. 
Thiobarbituric acid reactive substances. The spectrophotometric thiobarbituric acid assay used for the measurement of aldehyde lipid peroxidation products was that described by Wagner et al. (20). In this method, samples are incubated at $75^{\circ} \mathrm{C}$ for $30 \mathrm{~min}$ in $40 \%$ trichloroacetic acid and $1 \mathrm{~N} \mathrm{HCl}$. Supernatant fractions of reaction products are read at $532 \mathrm{~nm}$ using standards generated by the hydrolysis of 1,1,3,3-tetramethoxypropane.

Malondialdehyde. MDA was measured by modification of the method of Londero and LoGreco (21). Briefly, reaction mixtures for derivatization were prepared by adding $150 \mu \mathrm{L}$ of $0.44 \mathrm{M}$ phosphoric acid, $5 \mu \mathrm{L}$ of $50 \mathrm{mM}$ EDTA, $5 \mu \mathrm{L}$ of $2 \%$ butylated hydroxytoluene in ethanol, $10-25 \mu \mathrm{L}$ of sample or standard (1,1,3,3-tetraethoxypropane), and 40\% ethanol to a total volume of $185 \mu \mathrm{L}$. For experiments in which r-Hu-Lf, desferrioxamine, and ferrous sulfate were added to formula or human milk, samples were incubated for $1 \mathrm{~h}$ at room temperature. Disodium EDTA and butylated hydroxytoluene were added to reaction mixtures to prevent artifactual formation of MDA during the derivatization procedure (22). After a 10-min room temperature incubation, $50 \mu \mathrm{L}$ of $0.6 \%$ thiobarbituric acid was added to form the thiobarbituric acid-MDA analyte (TBA $\left.{ }_{2} \mathrm{MDA}\right)$. Reaction mixtures were subsequently heated to $95^{\circ} \mathrm{C}$ for $30 \mathrm{~min}$, and cooled to $4^{\circ} \mathrm{C}$ before neutralization with $0.5 \mathrm{M} \mathrm{KOH}$ in $50 \%$ (vol $/ \mathrm{vol})$ methanol. Samples were centrifuged at $16,000 \times g$ for $1-5 \mathrm{~min}$, and $20 \mu \mathrm{L}$ of supernatant were injected onto a $4.6 \times 150-\mathrm{mm}$ (Beckman Ultrasphere ODS, Fullerton, CA, U.S.A., $5 \mu \mathrm{m}$ ) analytical column with a $4.3 \times 10-\mathrm{mm}$ guard cartridge (Upchurch C-750, Oak Harbor, Washington, U.S.A.). The analytes were eluted at ambient temperature with $65 \% 50 \mathrm{mM}$ potassium phosphate buffer, $\mathrm{pH}$ 7.0. The thiobarbituric acid-MDA complex in the eluate was detected and quantified by fluorescence spectroscopy $\left(\lambda_{\mathrm{ex}}, 532\right.$ $\mathrm{nm} ; \lambda_{\mathrm{em}}, 553 \mathrm{~nm}$ ).

Ethane gas chromatography headspace assay. Ethane, a volatile, lipid peroxidation breakdown product of $\omega-3$ fatty acids, was measured using the method of Wagner et al. (20). Briefly, $5 \mathrm{~mL}$ of infant formula or human milk was placed in a 20-mL syringe previously purged with compressed air. A 6-mL headspace of compressed air was placed over the sample and sealed with a syringe plunger septum. The addition of the medicinal iron preparations was achieved by injection through the septum. Samples were mixed and incubated at $37^{\circ} \mathrm{C}$ for $2 \mathrm{~h}$, after which $1 \mathrm{~mL}$ of the sample was expressed through a 22-gauge needle to purge the needle's void volume with the remaining $5 \mathrm{~mL}$ of headspace gas being injected into a sampling loop containing 60/80 mesh Alumina F-1 (Supelco, Bellafonte, PA, U.S.A.). The trapped headspace gas in the sampling loop was then diverted into the injection port of a 5710A Hewlett Packard gas chromatograph. Using nitrogen as the carrier gas, chromatographic separations were run isothermally at $50^{\circ} \mathrm{C}$ at a flow rate of $20 \mathrm{~mL} / \mathrm{min}$ through a one-eighth inch $\times 5 \mathrm{~m} \mathrm{80/100}$ mesh Poracil C (Supelco) column and detected by flame ionization at $150^{\circ} \mathrm{C}$. Ethane levels were determined using a $14 \mathrm{ppm}$ methane, $14 \mathrm{ppm}$ propane, $14 \mathrm{ppm}$ butane, 14 ppm pentane gas as standard (Supelco).

\section{Data Analysis}

Statistical analyses were performed using commercial software (StatView 5.0, Abacus Concepts, Inc., Berkeley, CA, U.S.A.). Between-group comparisons were done using the unpaired $t$ test. For within- and between-group comparisons over time, one-factor and two-factor ANOVA with and without repeated measures procedures as appropriate were used. Only two-tailed significance testing was applied. The $\alpha$ level $<0.05$ was considered statistically significant. Comparisons with significant ANOVA $F$ values were subjected to post hoc testing using Dunnett's or Fisher's least significant difference method. Results are presented as the mean \pm SEM.

\section{RESULTS}

\section{Oxidation Products in Infant Formulas and Human Milk}

Asc.- free radical. Asc- ${ }^{-}$concentration was measured in five cow's milk-based formulas and in human milk before and after the addition of the iron binding agents apo-r-Hu-Lf and desferrioxamine (Table 1). Human milk had significantly lower Asc $^{--}$concentrations $(p<0.05)$ than any of the infant formulas. Compared with the Asc ${ }^{-}$concentration in human milk before the addition of the iron binding agents $\mathrm{Lf}$ and desferrioxamine, mean $\mathrm{Asc}^{--}$concentration for the combined group of infant formulas was significantly higher: $23 \pm 2 \mathrm{nM}, n=18$, versus $39 \pm 2, n=23$, respectively, $p<0.0001$. Enfamil Low Iron had significantly lower Asc ${ }^{--}$levels $(p<0.01)$ compared with Enfamil 20, 22, or 24 but it did not differ significantly when compared with Enfamil Premature With Iron $(p=0.13)$.

Table 1. Mean ascorbate radical concentration ( \pm SEM) in formula and human milk before and after the addition of iron binding agents

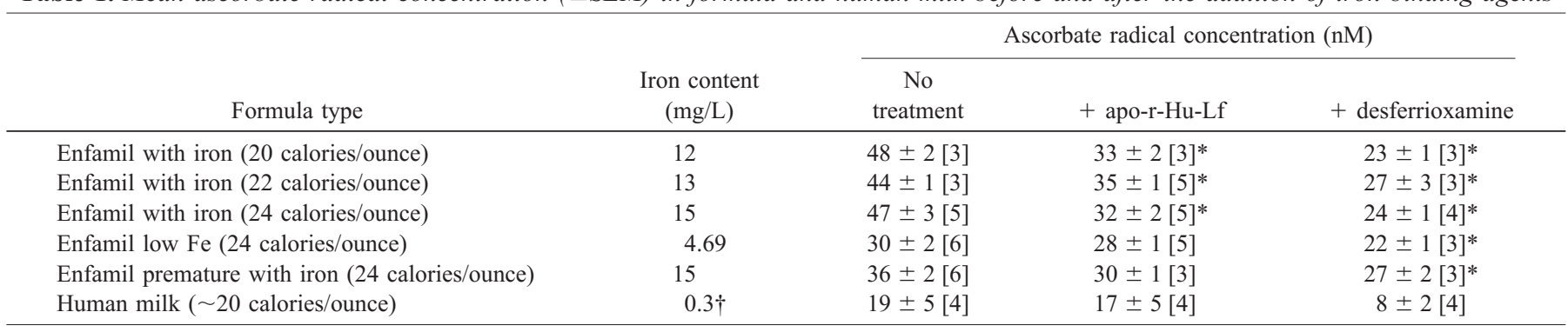

[] number of samples assayed.

$* p<0.05$ compared with no treatment.

$\dagger$ Estimated. 
The level of Asc- ${ }^{-}$was higher in term formula (Enfamil 20) compared with premature formula, although the latter contained slightly more iron (15 versus $12 \mathrm{mg}$ elemental iron/L). This may be the result of premature formula being fortified with higher concentrations of antioxidant vitamins $\mathrm{E}$ (50 versus $13 \mathrm{IU} / \mathrm{L}$ of the acetate form) and C (160 versus $80 \mathrm{mg} / \mathrm{L})$ than term formula.

POBN/ $\alpha-O H e t$ free radical. Although all of the infant formulas tested generated detectable levels of $\mathrm{POBN} / \alpha$-OHet, this radical was undetectable in human milk. POBN $/ \alpha-\mathrm{OHet}$ levels were measurable in iron-fortified term (standard ironfortified $20 \mathrm{cal} /$ ounce) and premature formulas (iron-fortified $24 \mathrm{cal} /$ ounce) but these levels were not different: $1.34 \pm 0.02$ $\mu \mathrm{M}, n=8$, and $1.40 \pm 0.04 \mu \mathrm{M}, n=9$, respectively, $p<$ 0.13 .

In contrast, both the term and premature iron-fortified formulas had significantly higher POBN $/ \alpha-\mathrm{OHet}$ concentrations than low iron formula, $0.51 \pm 0.02 \mu \mathrm{M}, n=6, p<0.0001$.

Lipid peroxidation products. All three indicators of lipid peroxidation demonstrated that premature infant formula was associated with greater lipid peroxidation than human milk. TBARS were below the limit of detection in human milk but were easily detectable in premature formula, i.e., $3.75 \pm 0.28$ $\mathrm{nmol} / \mathrm{mL}, n=3$. Similarly, although MDA was detectable in both human milk and premature formula, its concentration was significantly less in human milk than in premature formula: $0.29 \pm 0.04 \mu \mathrm{M}, n=4$, versus $3.38 \pm 0.47 \mu \mathrm{M}, n=8$, respectively, $p<0.0001$. Ethane levels were below the limit of detection in human milk, most likely because $\omega-3$ fatty acids constitute $<1 \%$ of the fatty acids in human milk of North American women (23). With its 3.1\% $\omega-3$ fatty acids, premature formula demonstrated measurable- but low-levels of ethane, i.e. $<20 \mathrm{pmol} / \mathrm{mL}$. Thus, iron-fortified infant formulas generate significantly higher concentrations of free radicals and lipid peroxidation products than human milk.

\section{Medicinal Iron Supplements Increase Oxidation Products in Human Milk and Formula}

Asc- free radical. Because of the lowering effect of $\mathrm{pH}$ on $\mathrm{Asc}^{-}$, the $\mathrm{pH}$ was measured in medicinal iron preparations before and after their addition to human milk and formula. At $\mathrm{pH}<6.5$ (approximately), the $\mathrm{Asc}^{--}$is increasingly more difficult to detect because of its more rapid rate of dismutation and slower rate of formation $(15,24)$. The $\mathrm{pH}$ of human milk before the addition of medicinal iron ranged from 7.12 to 7.24 whereas that for infant formula ranged between 6.70 and 6.83 . The $\mathrm{pH}$ of the medicinal iron preparations before their addition to premature formula or human milk were ferrous sulfate, 1.70; ferric ammonium citrate, 4.50; ferrous fumarate, 4.75; ferric polymaltose, 6.00; iron polysaccharide complex $(\mathrm{Nu}$ Iron, polysaccharide "A"), 6.30; iron polysaccharide complex (NiFe-rex, polysaccharide "B"), 6.76; and iron polysaccharide complex (May Vita, polysaccharide "C"), 8.00.

The final $\mathrm{pH}$ of human milk or formula with ferrous sulfate, ferric ammonium citrate, or ferrous fumarate ranged between 5.8 and 6.5 whereas that for the three iron polysaccharide preparations ranged between 6.6 and 7.2. Because of $\mathrm{pH}$ interference with $\mathrm{Asc}^{--}$detection, data for the human milk and formula samples containing added iron that decreased the $\mathrm{pH}$ to $<6.5$ are not reported. In contrast, when the three polysaccharide iron formulations were added to milk or formula that allowed the maintenance of a near neutral $\mathrm{pH}$, a clear dosedependent increase in $\mathrm{Asc}^{--}$was observed (Fig. 1).

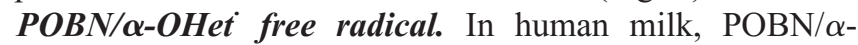
OHet radical levels remained below the limit of detection after adding either 2 or $6 \mathrm{mg} / \mathrm{kg}$ of iron polysaccharide complex "C." In contrast, significant increases in POBN $/ \alpha$-OHet levels were observed when iron polysaccharide complex " $\mathrm{C}$ " was added to term infant formula ( $p<0.0001$; Fig. 2).

Lipid peroxidation products. After the addition of all seven medicinal iron preparations, TBARS demonstrated significant increases both in human milk and in premature infant formula (Fig. 3). The increases in TBARS had a tendency to be dose related - although the magnitude of the stepwise increase in going from 2 to $6 \mathrm{mg}$ iron $/ \mathrm{kg}$ was not uniform for all iron preparations tested. Like TBARS levels, MDA levels increased

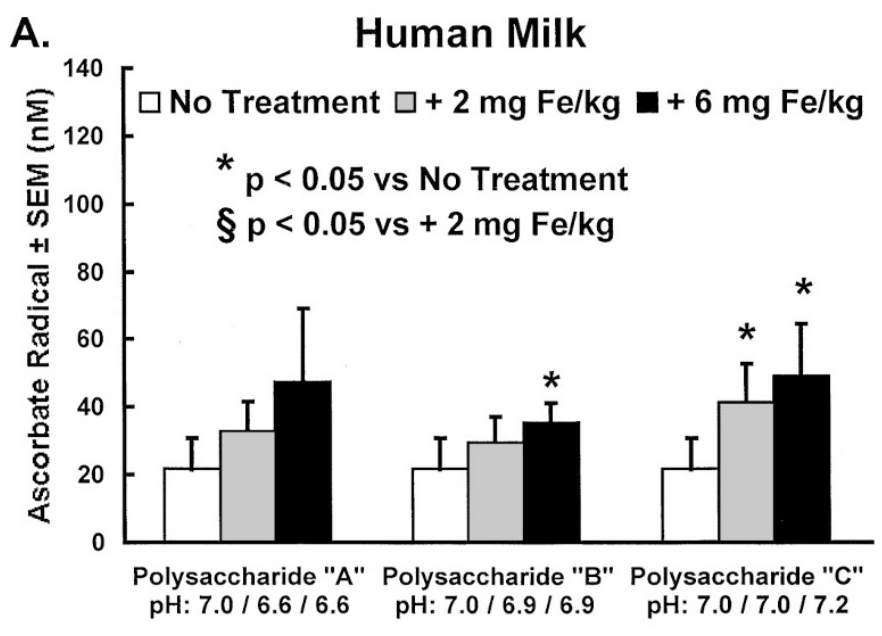

\section{B. Premature Infant Formula}

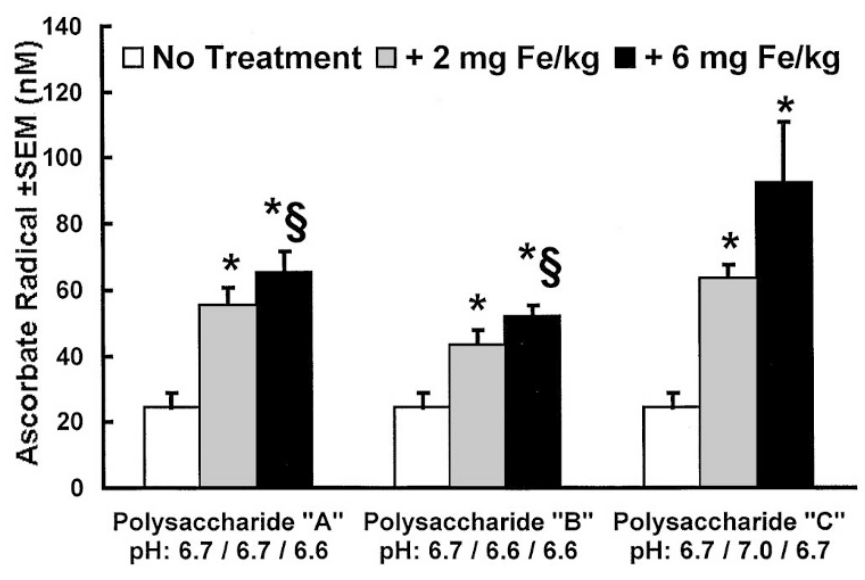

Figure 1. Asc ${ }^{-}$increased in human milk $(A)$ and premature infant formula $(B)$ after the addition of $2 \mathrm{mg}$ and $6 \mathrm{mg}$ elemental iron per kilogram body weight daily of a hypothetical $1.5-\mathrm{kg}$ premature infant. Following the name of the iron preparation are the final $\mathrm{pH}$ values in the sample after no treatment, and after the addition of $2 \mathrm{mg}$ and $6 \mathrm{mg} / \mathrm{kg}$ iron, respectively. Three paired replicates were measured for each preparation. Values are expressed as mean \pm SEM. 
Term Infant Formula

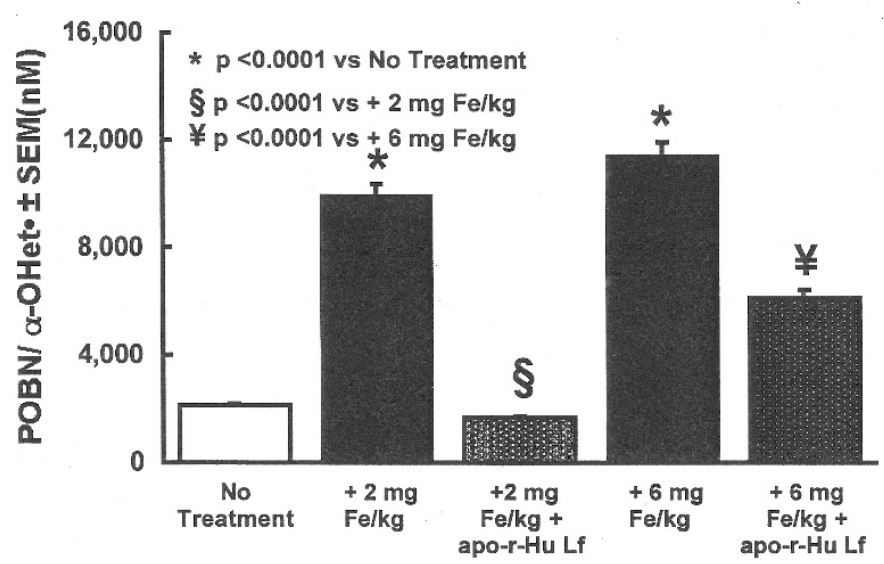

Figure 2. POBN $/ \alpha$-OHet levels were measured in term infant formula before treatment $(n=4)$ and after the addition of $2(n=4)$ or $6 \mathrm{mg}(n=3)$ elemental iron per kilogram body weight daily of a hypothetical $1.5-\mathrm{kg}$ premature infant. The POBN $/ \alpha$-OHet levels were also measured after the addition of apo-r$\mathrm{Hu}-\mathrm{Lf}$ (final concentration $150 \mu \mathrm{M}$ ) to the samples containing iron-fortified term formula and medicinal iron at $2(n=4)$ or $6 \mathrm{mg}(n=3)$. The iron concentrations in the samples were as follows: infant formula, $109 \mu \mathrm{M}$; infant formula with $2 \mathrm{mg} / \mathrm{kg} / \mathrm{d}, 1.45 \mathrm{mM}$; and infant formula with $6 \mathrm{mg} / \mathrm{kg} / \mathrm{d}, 4.13$ $\mathrm{mM}$.

in a stepwise manner in both human milk and premature infant formula after the addition of ferrous sulfate at 2 and $6 \mathrm{mg} / \mathrm{kg}$ estimated body weight $(p<0.001$; Fig. 4$)$. The absolute levels of MDA were uniformly lower in human milk than for premature infant formula, with the magnitude of the percentage increase from baseline in the MDA level being higher in human milk than formula $(p<0.0001)$. Ethane concentrations in human milk were below the limit of detection after adding any of the seven medicinal iron preparations. In contrast, all seven of the iron preparations increased ethane levels in formula. Although mean ethane levels in premature formula were significantly $(p<0.005)$ higher after adding either 2 or $6 \mathrm{mg}$ iron $/ \mathrm{kg}$, a dose-dependent increase was not observed (Fig. 5). These data indicate that the addition of medicinal iron to human milk or formula leads to a significant rise in ironinduced free radical generation and lipid peroxidation products.

\section{HMF Containing Iron Increases Free Radicals in Human Milk}

Iron-containing HMF added to human milk resulted in significantly higher $\mathrm{Asc}^{-}$levels compared with human milk alone, i.e. $54 \pm 3$ versus $23 \pm 3 \mathrm{nM}, n=5, p=0.002$. Although POBN $/ \alpha$-OHet radical adducts were below the limit of detection in human milk before the addition of HMF, $n=$ 11 , after its addition, $\alpha$-OHet radicals were easily measurable, i.e. $2200 \pm 100 \mathrm{nM}, n=3$. Lipid peroxidation products were not measured in human milk samples after the addition of HMF.

\section{Apo-r-Hu-Lf Supplementation Attenuates Oxidation}

Asc.- free radical. The addition of apo-r-Hu-Lf in a final concentration of $87 \mu \mathrm{M}$ significantly decreased $(p<0.05)$ the
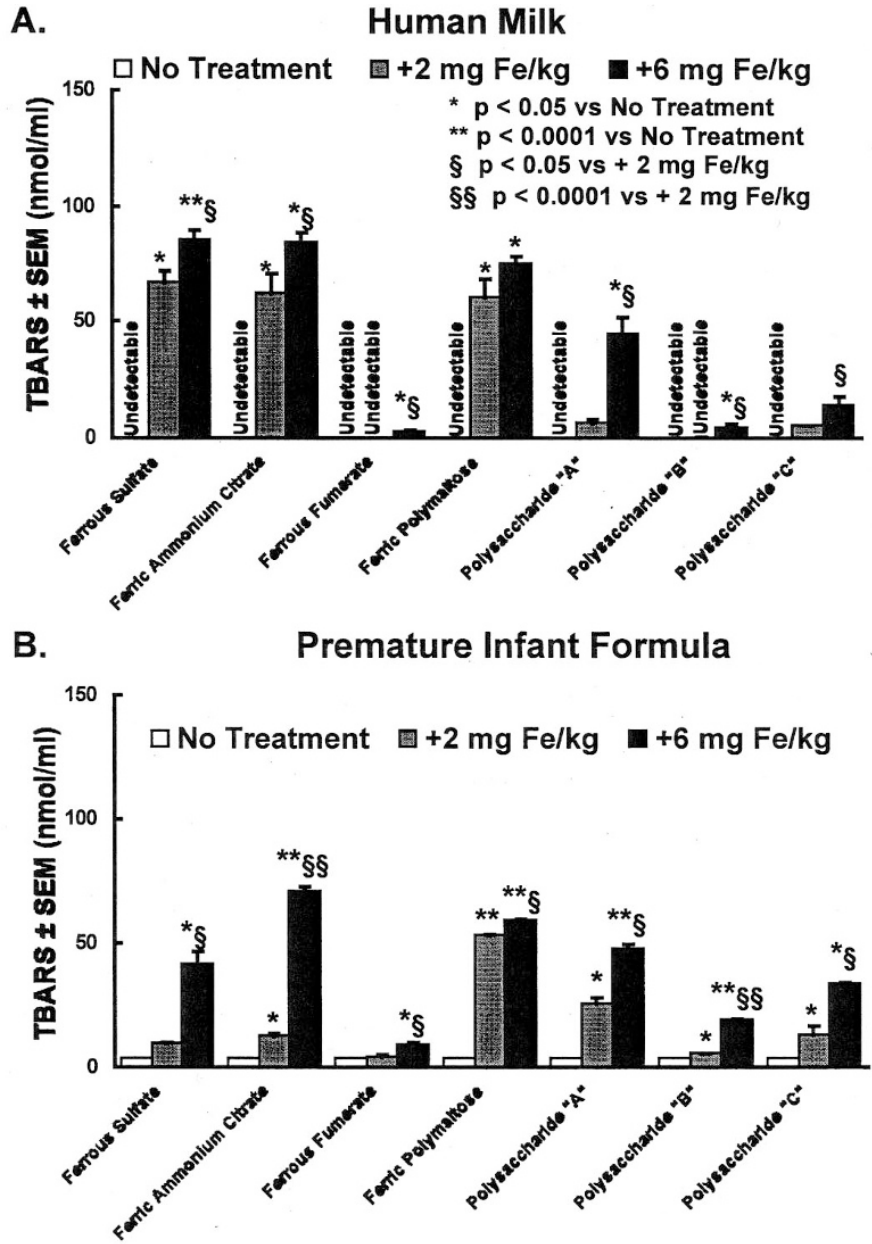

Figure 3. TBARS increased in human milk $(A)$ and premature infant formula $(B)$ after the addition of all medicinal iron preparations at both $2 \mathrm{mg}$ and $6 \mathrm{mg}$ elemental iron per kilogram body weight daily of a hypothetical $1.5-\mathrm{kg}$ premature infant. Three paired replicates were measured for each iron preparation. Values are expressed as mean \pm SEM.

level of $\mathrm{Asc}^{--}$in infant formula in three of the five formulas studied, but not in human milk ( $p=0.78$; Table 1). Similarly, the addition of the cationic chelator, desferrioxamine, to either formula or human milk in a final concentration of $28 \mathrm{mM}$ also resulted in a decrease in Asc ${ }^{--}$levels in formula $(p<0.05)$, but not for human milk $(p=0.10)$.

POBN/ $\alpha-$ OHet free radical. Because POBN $/ \alpha-O H e t$ radicals were below the limit of detection in untreated human milk, $\mathrm{r}$-Hu-Lf experiments were not performed. However, when iron-containing HMF was added to human milk, r-Hu-Lf blunted the increase in POBN levels from $2200 \pm 100 \mathrm{nM}, n$ $=3$, to $1250 \pm 80 \mathrm{nM}, n=3, p=0.0023$. The addition of r-Hu-Lf to term formula in a final concentration of $166 \mu \mathrm{M}$ resulted in significantly decreased levels of POBN $/ \alpha$-OHet $(p$ $<0.0001$; Fig. 6). r-Hu-Lf was also added to term infant formula in a final concentration of $150 \mu \mathrm{M}$ followed by the addition of 2 and $6 \mathrm{mg} / \mathrm{kg}$ of medicinal iron. POBN $/ \alpha-\mathrm{OHet}$ levels were significantly decreased at both iron concentrations $(p<0.0001$; Fig. 2).

Lipid peroxidation products. The addition of apo-r-Hu-Lf in a final concentration of $87 \mu \mathrm{M}$ to premature formula did not 
A.

Human Milk

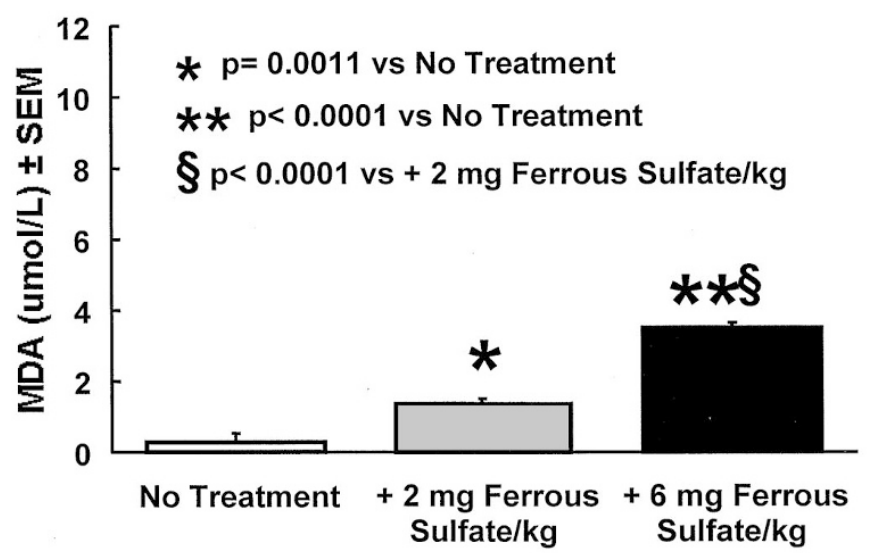

B.

Premature Infant Formula

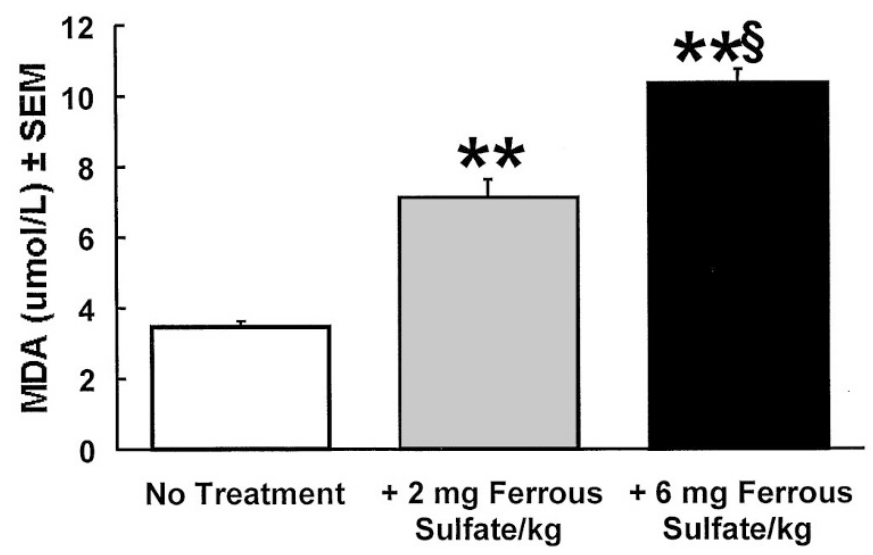

Figure 4. MDA levels increased in human milk $(A, n=3)$ and premature infant formula $(B, n=7)$ after the addition of ferrous sulfate at both $2 \mathrm{mg}$ and $6 \mathrm{mg}$ elemental iron per kilogram body weight daily of a hypothetical $1.5-\mathrm{kg}$ premature infant. Values are expressed as mean \pm SEM.

decrease the basal level of MDA, i.e. $3.14 \pm 0.12, n=3$, versus $3.32 \pm 0.17 \mu \mathrm{M}, n=9$. However, the addition of apo-r-Hu-Lf did prevent the increase of MDA measured in premature formula after the addition of ferrous sulfate. Initial MDA levels in premature formula after adding 2 or $6 \mathrm{mg} / \mathrm{kg}$ estimated body weight of ferrous sulfate were $6.88 \pm 0.42, n$ $=9$, and $10.13 \pm 0.35, n=9$, respectively. MDA levels in these formula with the concurrent addition of r-Hu-Lf $(87 \mu \mathrm{M})$ and 2 or $6 \mathrm{mg} / \mathrm{kg}$ of iron were significantly lower, i.e. $5.16 \pm$ $0.03 \mu \mathrm{M}, n=3, p=0.04$, and $7.95 \pm 0.04 \mu \mathrm{M}, n=3, p=$ 0.006 , respectively.

Apo-r-Hu-Lf Attenuates Free Radical Production When Added to Term Formula Significantly More Than

\section{Holo-r-Hu-Lf}

Although both iron-unsaturated apo-r-Hu-Lf and the ironsaturated holo-r-Hu-Lf, significantly $(p<0.0001)$ decreased the concentration of POBN $/ \alpha$-OHet radicals in term formula, there was a significantly $(p<0.0001)$ greater decrease when apo-r-Hu-Lf $(166 \mu \mathrm{M})$ was added compared with holo-r-Hu-Lf (166 $\mu \mathrm{M}$; Fig. 6). Desferrioxamine $(174 \mu \mathrm{M})$ decreased the
Premature Infant Formula

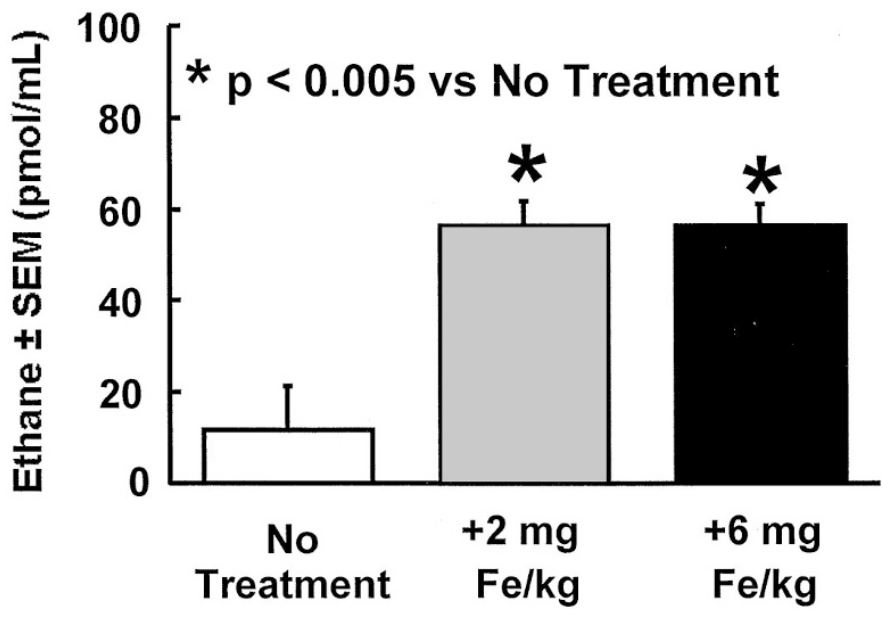

Figure 5. Ethane in premature infant formula significantly $(p<0.005)$ increased after the addition of all seven medicinal iron preparations at both 2 $\mathrm{mg}$ and $6 \mathrm{mg}$ elemental iron per kilogram body weight daily of a hypothetical $1.5-\mathrm{kg}$ premature infant. Human milk has very low levels of $\omega-3$ fatty acids, and ethane levels were undetectable before and after the addition of medicinal iron. Three paired replicates were measured for each iron preparation. Values are expressed as mean \pm SEM.

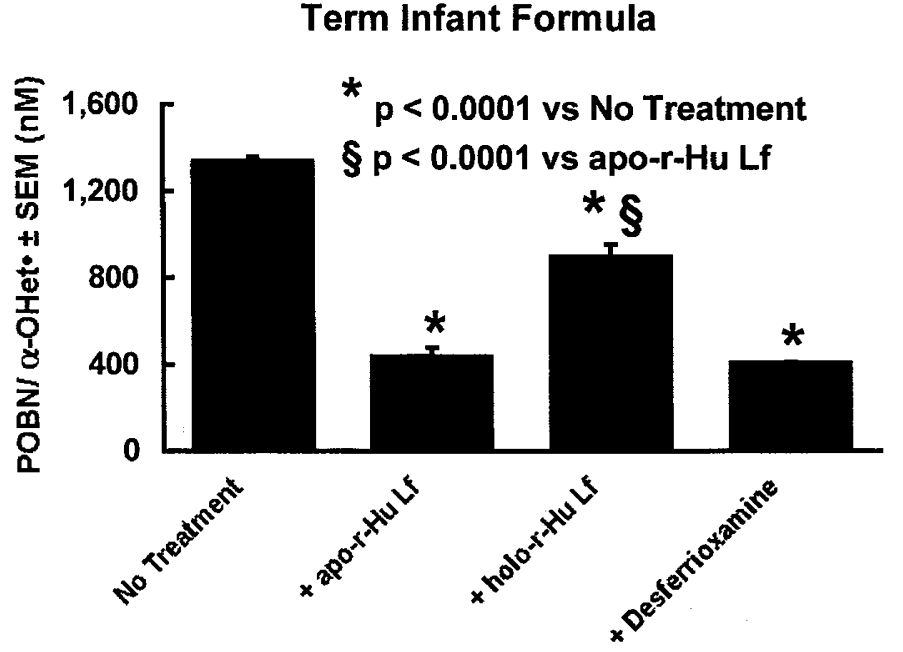

Figure 6. POBN $/ \alpha-\mathrm{OHet}$ levels in term infant formula were measured before treatment $(n=8)$, and after the addition of iron-unsaturated apo-r-Hu-Lf (158 $\mu \mathrm{M} ; n=7)$, iron-saturated holo-r-Hu-Lf $(158 \mu \mathrm{M} ; n=7)$, or desferrioxamine $(174 \mu \mathrm{M} ; n=3)$. The iron concentration in the samples was $146 \mu \mathrm{M}$. Values are expressed as mean \pm SEM.

level of POBN $/ \alpha-\mathrm{OHet}$ to the same degree as apo-r-Hu-Lf did. Thus, the reduction of iron-mediated oxidation products is likely a result of the binding of iron by apo-r-Hu-Lf, thereby preventing iron from chemically reacting with oxygen and lipids.

\section{DISCUSSION}

The principal finding of our study is that iron-induced oxidation products abound in iron-fortified formulas and increase further after the addition of medicinal iron supplements. Although human milk showed less of iron-induced oxidation 
products compared with infant formula, oxidation products in human milk increased significantly after the addition of medicinal iron or iron-containing HMF. From the decrease in free radical production observed after the addition of the ironbinding protein Lf, we speculate that these oxidation products are primarily generated by iron catalysis.

Although it is recommended that premature infants receive at least $2-4 \mathrm{mg} / \mathrm{kg} / \mathrm{d}$ of iron to prevent iron deficiency anemia (25), high amounts of iron added to the diet have been shown to decrease serum ceruloplasmin (26) and copper-zinc SOD levels in erythrocytes (27). These effects may be the result of adverse effects on copper metabolism from excess iron. Iron supplements have been shown to generate oxidation products via iron-oxygen chemistry (2), but may also decrease the levels of the antioxidants ceruloplasmin and SOD. Low ceruloplasmin and SOD levels could predispose the premature infant to significant oxidative stress. These potential untoward effects of higher dose iron supplementation might be reduced by the inclusion of Lf in infant formula.

Absorption of enteral iron requires the oxidation of iron from the ferrous to the ferric state by intestinal xanthine oxidase (28). Reactions catalyzed by xanthine oxidase result in the generation of superoxide and hydroxyl radical that in turn contribute to the pool of oxidant products to which the gut is exposed. Glutathione-dependent mechanisms may have a protective role in the metabolism of luminal hydroperoxides (29). However, the role of glutathione-dependent mechanisms in the gut of the preterm infant is uncertain as this has not been studied in preterm infants receiving high-dose iron supplementation.

Infants weighing less than $1500 \mathrm{~g}$ at birth are at risk for iron deficiency because their adequate stores of iron at birth are rapidly depleted by their subsequent rapid weight gain in association with a concomitant increase in their erythrocyte mass (5). Data from Hall et al. (30) demonstrated that infants weighing less than $1800 \mathrm{~g}$ at birth and receiving a low-iron content premature formula demonstrated evidence of iron deficiency at the time of hospital discharge compared with infants receiving high-iron content premature formula. Although iron deficiency affects a wide spectrum of biochemical and hematologic functions, of most concern is its association with adverse behavioral and developmental outcomes (31). Although these data suggest an important role of iron supplements in low birth weight infants approaching discharge home, the timing of when after birth iron supplementation should be started is likely a more important question than whether it should be started. Although there is agreement that enteral iron supplementation should be provided, the present data suggest that the timing of this be put off until the infant is at lower risk for sustaining the complications that have been suggested as being associated with oxidation processes that iron is capable of exacerbating, e.g. intraventricular hemorrhage, periventricular leukomalacia, retinopathy of prematurity, bronchopulmonary dysplasia, and necrotizing enterocolitis. This may be especially important because iron released from $\mathrm{Hb}$ in packed red blood cell transfusions is a major source of iron in the initial 6-8 wk of life (32) for very low birth weight premature infants. Consequently, in the early weeks of life, premature infants may encounter excess iron more often than a deficiency (33).

The increased level of iron-induced oxidation products we observed in human milk and infant formulas substantiates previous findings in primates of potential harm from formulas containing $12 \mathrm{mg}$ iron/L (26). In our study, oxidation products were measured in infant formulas containing 4.7, 12, 13, and $15 \mathrm{mg}$ iron/L, with the results showing a trend toward an increase in oxidation products with increasing iron concentrations in the formulas studied.

Furthermore, on the basis of the results of clinical studies showing no demonstrable benefit of improved iron status, Fomon et al. (34) and Hertrampf et al. (35) both recommended decreasing the iron content in iron-fortified infant formulas from 12 to $8 \mathrm{mg}$ iron/L. Similarly, the American Academy of Pediatrics has stated that iron supplementation has no demonstrable impact on anemia of prematurity occurring in the first months of life (3). Hence, although there is higher absolute amount of iron absorbed with the high iron formulas, there is a greater potential for iron-induced oxidation damage. Among preterm infants whose antioxidant systems may be less effective than those of their term counterparts, these circumstances could contribute to an increased propensity for oxidative damage.

Although the bacteriostatic (36), bactericidal $(37,38)$, and fungistatic (39) properties of Lf have been well established, free radical production has not, to our knowledge, been previously studied in human milk or formula after the addition of Lf. In the current study, the addition of medicinal iron and ironcontaining HMF to human milk resulted in a significant increase in $\mathrm{Asc}^{-}$and the appearance of POBN/ $\alpha-\mathrm{OHet}$, which had not been previously detected. The 2-mg iron $/ \mathrm{kg}$ body weight added to human milk or formula in the present experiments reflects the lower end of the dose currently recommended by the American Academy of Pediatrics (10). The $6-\mathrm{mg} / \mathrm{kg}$ dose was chosen to simulate the dose of iron supplements used in clinical trials in conjunction with recombinant human erythropoietin (40) and is similar to the dose administered to preterm infants in some centers (41).

Previous studies have demonstrated the presence of lipid peroxidation products in infant formulas and human milk (42-44). In the present study, we have confirmed that the lipid peroxidation products, MDA, TBARS, and ethane, are present in greater quantities in infant formula relative to human milk after exposure to ambient oxygen. After the addition of medicinal iron or iron-containing HMF to both human milk and infant formula, we observed that free radical lipid peroxidation products - most likely the result of free radical-mediated injury-had increased significantly.

Findings of the present study are consistent with the speculation that the observed increases in free radical production and in fatty acid peroxidation are the result of the pro-oxidant properties of unbound iron. The rationale for this is that free iron is bound by the two high-affinity iron-binding sites on Lf, an endogenously produced protein found in high concentrations in breast milk and other body fluids. Several observations in the present study support this speculation. First, in addition to the low concentration of iron normally present in human milk, the presence of endogenous 
Lf may have been a contributor to the lower free radical concentrations observed in human milk relative to formula. Second, the observation that the addition of apo-r-Hu-Lf to human milk with added iron-containing HMF blunted the increase of POBN $/ \alpha$ OHet of HMF alone adds further support of this speculation. The third piece of supporting data comes from the observation that after the addition of medicinal iron with resultant $\mathrm{pHs}>6.5$ (approximately), dose-dependent elevations of iron-induced free radicals and oxidation products were observed. Fourth, when apo-r-Hu-Lf was added to human milk with HMF or formula with medicinal iron added, both showed a significant reduction in free radical production. Although we observed a significant attenuation of free radical formation with the addition of apo-r-Hu-Lf at iron:Lf molar ratios $>2$, an attenuation of lipid peroxidation products present in infant formula has been previously reported by Satué-Gracia et al. (44). These authors fortified infant formula with bovine $\mathrm{Lf}$ and observed attenuated lipid peroxidation at all molar ratios studied, i.e. up to 18 . These authors demonstrated that this peroxidation effect was an Lf-specific effect and postulated that it was caused by the binding of iron to Lf at sites other than the two high-affinity iron binding receptors of Lf as previously shown by Nagasako et al. (45). As such, binding of iron to sites other than the two high-affinity iron binding sites of Lf may have been responsible for the decrease we observed in POBN $/ \alpha-\mathrm{OHet}$ adducts after the addition of iron-saturated holo-r-Hu-Lf.

Bovine Lf-fortified infant formulas used in previous clinical trials were well tolerated $(46,47)$. Dietary Lf is minimally hydrolyzed in the preterm infant's stomach (48), with some Lf persisting during transit through the bowel (49). The presence of Lf-specific receptors in the human intestine (50) suggests a physiologic role for Lf and makes it likely that Lf supplementation of formula would be tolerated. An in vivo study in rats by Nimmagudda et al. (51) showed that Lf provides cytoprotection in limiting mediated free radical injury of the gastrointestinal tract. In another study, iron supplementation has been shown to generate hydroxyl radicals in vivo in rats (52). What remains to be shown is whether human Lf added to formula protects the intestinal mucosa of preterm infants from ironinduced oxidation products in vivo.

\section{CONCLUSIONS}

In summary, medicinal iron supplements added to formula and HMF containing iron added to human milk increased free radical generation and lipid peroxidation. These effects were diminished with the addition of r-Hu-Lf. Because ours was an in vitro study, there are limitations in extrapolating the present findings to very premature infants. Nonetheless, our in vitro findings raise questions regarding the potential for iron supplementation to have significant oxidant effects. Our findings also suggest a therapeutic role for $\mathrm{Lf}$ in attenuating oxidant effects of iron supplementation. Future in vivo studies defining the role of enteral iron in oxidant injury in preterm and term infants are needed before the potential benefits of human Lf in decreasing iron-induced oxidative injury are explored.

Acknowledgments. The authors thank Agennix for the gift of recombinant human Lf (apo and holo), mothers who gener- ously donated breast milk for this study, and Tracy L. Tud, R.N., who helped collect the human milk samples. We also thank Bradley E. Britigan, M.D., for his encouragement and guidance during the study and Ekhard E. Ziegler, M.D., and Larry W. Oberley, Ph.D., for stimulating discussions.

\section{REFERENCES}

1. Saugstad OD 1990 Oxygen toxicity in the neonatal period. Acta Paediatr 79:881-892

2. Qian SY, Buettner GR 1999 Iron and dioxygen chemistry is an important route to initiation of biological free radical oxidations: an electron paramagnetic resonance spin trapping study. Free Radic Biol Med 26:1447-1456

3. American Academy of Pediatrics Committee on Nutrition 1999 Iron fortification of infant formulas. Pediatrics 104:119-123

4. Gorten MK, Cross ER 1964 Iron metabolism in premature infants. II. Prevention of iron deficiency. Pediatrics 64:509-520

5. Worwood M 1977 The clinical biochemistry of iron. Semin Hematol 14:3-30

6. Frank L, Sosenko I 1991 Failure of premature rabbits to increase antioxidant enzymes during hyperoxic exposure: increased susceptibility to pulmonary oxygen toxicity compared with term rabbits. Pediatr Res 29:292-296

7. Smith CV, Hansen TN, Martin NE, McMicken HW, Elliott SJ 1993 Oxidant stress responses in premature infants during exposure to hyperoxia. Pediatr Res 34:360-365

8. Sullivan JL, Newton RB 1988 Serum antioxidant activity in neonates. Arch Dis Child 63:748-757

9. Varsila E, Hallman M, Anderson S 1994 Free-radical-induced lipid peroxidation during the early neonatal period. Acta Paediatr 83:692-695

10. American Academy of Pediatrics Committee on Nutrition 1985 Nutritional needs and feeding of premature infants. Pediatrics 75:976-986

11. Ramasethu J, Gunter KC, McClenny RP, Luban NLC, Fletcher AB 1997 When is iron supplementation appropriate for the extremely low birth weight infant? Pediatr Res 41:239A(abstr)

12. Gutteridge JM, Paterson SK, Segal AW, Halliwell B 1981 Inhibition of lipid peroxidation by the iron-binding protein lactoferrin. Biochem J 199:259-261

13. Lewis-Jones DI, Lewis-Jones MS, Connolly RC, Lloyd WCR 1985 Sequential changes in the antimicrobial protein concentrations in human milk during lactation and its relevance to banked human milk. Pediatr Res 19:561-565

14. Sharma MK, Buettner GR, Spencer KT, Kerber RE 1994 Ascorbyl free radical as a real-time marker of free radical generation in briefly ischemic and reperfused hearts: an electron paramagnetic resonance study. Circ Res 74:650-658

15. Buettner GR, Jurkiewiz BA 1993 Ascorbate free radical as a marker of oxidative stress: an EPR study. Free Radic Biol Med 14:49-55

16. Buettner GR, Mason RP 1990 Spin-trapping methods for detecting superoxide and hydroxyl free radicals in vitro and in vivo. Methods Enzymol 186:127-133

17. Venkataramon S, Martin SM, Schafer FQ, Buettner GR 2000 Detailed methods for the quantification of nitric oxide in aqueous solutions using either an oxygen monitor or EPR. Free Radic Biol Med 29:580-585

18. Buettner GR, Kiminyo KP 1992 Optimal EPR detection of weak nitroxide spin adduct and ascorbyl free radical signals. J Biochem Biophys Methods 24:147-151

19. Friel JK, Martin SM, Langdon M, Herzberg GR, Buettner GR 2002 Milk from mothers of both premature and full-term infants provides better antioxidant protection than does infant formula. Pediatr Res 51:612-618

20. Wagner BA, Buettner GR, Oberley LW, Darby CJ, Burns PC 2000 Myeloperoxidase is involved in $\mathrm{H}_{2} \mathrm{O}_{2}$-induced apoptosis of HL-60 human leukemia cells. J Biol Chem 275:22461-22469

21. Londero D, LoGreco P 1996 Automated high-performance lipid chromatographic separation with spectrofluorometric detection of a malondialdehyde thiobarbituric acid adduct in plasma. J Chromatogr A 729:207-210

22. Suttnar J, Masova L, Dyr JE 2001 Influence of citrate and EDTA anticoagulants on plasma malondialdehyde concentrations estimated by high-performance liquid chromatography. J Chromatogr B Biomed Appl 751:193-197

23. ESPGAN Committee on Nutrition 1990 Committee report. Comment on the content and composition of lipids in infant formulas. Acta Paediatr 80:887-896

24. Bors W, Buettner GR 1997 The vitamin C radical and its reactions. In: Packer L, Fuchs J (eds) Vitamin C in Health and Disease. Marcel Dekker, Inc., New York, pp 75-94

25. Siimes MA, Jarvenpaa A 1982 Prevention of anemia and iron deficiency in verylow-birth-weight infants. J Pediatr 101:277-280

26. Lonnerdal B, Kelleher SL, Lien EL 2001 Extent of thermal processing infant formula affects copper status in infant rhesus monkeys. Am J Clin Nutr 73:914-919

27. Barclay SM, Aggett PJ, Lloyd DJ, Duffy P 1991 Reduced erythrocyte superoxide dismutase activity in low birth weight infants given iron supplements. Pediatr Res 29:297-301

28. Parks DA, Granger DN 1986 Xanthine oxidase: biochemistry, distribution and physiology. Arch Dis Child 64:1621-1628

29. Aw TY, Williams MW 1992 Intestinal absorption and lymphatic transport of peroxidized lipids in rats: effect of exogenous GSH. Am J Physiol 263:G665-G672

30. Hall RT, Wheeler RE, Benson J, Harris G, Rippetoe L 1993 Feeding iron-fortified premature formula during initial hospitalization to infants less than 1800 grams birth weight. Pediatrics 92:409-414

31. Grantham-McGregor S, Ani C 2001 A review of studies on the effect of iron deficiency on cognitive development in children. J Nutr 131:649S-666S

32. Committee on Nutrition of the Preterm Infant 1987 Nutrition and feeding of the preterm infant. Acta Paediatr 336:10-11 
33. Aggett PJ 2001 Trace elements of the micropremie. Clin Perinatol 27:119-129

34. Fomon SJ, Ziegler EE, Serfass RE, Nelson SE, Frantz JA 1997 Erythrocyte incorporation of iron is similar from infant formulas fortified with $12 \mathrm{mg} / \mathrm{L}$ or $8 \mathrm{mg} / \mathrm{L}$ of iron. J Nutr 127:83-88

35. Hertrampf E, Olivares M, Pizzaro P, Walter T 1998 High absorption of fortification iron from current infant formulas. J Pediatr Gastroenterol Nutr 27:425-430

36. Oram JB, Rieter B 1968 Inhibition of bacteria by lactoferrin and other iron-chelating agents. Biochim Biophys Acta 170:351-365

37. Arnold RR, Cole MF, McGhee JR 1977 A bactericidal effect for human lactoferrin. Science 197:263-265

38. Bullen JJ, Armstrong JA 1979 The role of lactoferrin in the bactericidal function of polymorphonuclear leukocytes. Immunology 36:781-791

39. Kuipers ME, deVries HG, Eikelboom MC, Meijer DKF, Swart PH 1999 Synergistic fungistatic effects of lactoferrin in combination with antifungal drugs against clinica Candida isolates. Antimicrob Agents Chemother 43:2635-2641

40. Shannon K 1993 Recombinant erythropoietin in anemia of prematurity: five years later. Pediatrics 92:614-617

41. Barclay SM, Lloyd DJ, Duffy P, Aggett PJ 1989 Iron supplements of preterm or low birthweight infants. Arch Dis Child 64:1621-1628

42. Marshall TA, Roberts RJ 1990 In vitro and in vivo assessment of lipid peroxidation of infant nutrient preparations: effect of nutrition on oxygen toxicity. J Am Coll Nutr 9:190-199

43. Zoeren-Grobben DV, Moison RMW, Ester WM, Berger HM 1993 Lipid peroxidation in human milk and infant formula: effect of storage, tube feeding and exposure to phototherapy. Acta Paediatr 82:645-649
44. Satué-Gracia MT, Frankel EN, Rangavajhyala N, German JB 2000 Lactoferrin in infant formulas: effect on oxidation. J Agric Food Chem 48:4984-4990

45. Nagasako Y, Saito H, Tamura Y, Shimamura S, Tomita M 1993 Iron-binding properties of bovine lactoferrin in iron-rich solution. J Dairy Sci 76:18761881

46. Balmer SE, Wharton BA 1989 Diet and faecal flora in the newborn: lactoferrin. Arch Dis Child 64:1685-1690

47. Roberts AK, Chierci R, Sawazki G, Hill MJ, Volpato S, Vigi V 1992 Supplementation of an adapted formula with bovine lactoferrin. 1. Effect on the infant faecal flora. Acta Paediatr 81:119-124

48. Britton JR, Koldovsky O 1989 Gastric luminal digestion of lactoferrin and transferrin by preterm infants. Early Hum Dev 19:127-135

49. Schanler RJ, Goldblum RM, Garza C, Goldman AS 1986 Enhanced fetal excretion of secreted immune factors in very low birth weight infants fed fortified human milk. Pediatr Res 20:711

50. Cox TM, Mazurier J, Spik G, Montreuil J, Peters TF 1979 Iron binding proteins and influx of iron across duodenal brush border. Evidence for specific lactotransferrin receptors in the human intestine. Biochim Biophys Acta 588:120-128

51. Nimmagudda R, Bagchi D, Bagchi M, Tran MX, Steijnsj J, Braun S 1999 Cytoprotection by lactoferrin in oxygen radical mediated gastrointestinal injury. Biochem Arch 15:323-336

52. Kadiiska MB, Burkitt MJ, Xiang QH, Mason RP 1995 Iron supplementation generates hydroxyl radical in vivo: an ESR spin-trapping investigation. J Clin Invest 96:1653-1657 